\title{
Antibacterial capacity of cavity disinfectants against Streptococcus mutans and their effects on shear bond strength of a self-etch adhesive
}

\author{
Han-Sol CHA and Dong-Hoon SHIN \\ Department of Conservative Dentistry, Graduate School, DanKook University, Dandaero \#119, Anseo-dong, Dongnam-gu, Cheonan, Chungnam \\ 330-714, Korea \\ Corresponding author, Dong-Hoon SHIN; E-mail: donyshin@dankook.ac.kr
}

\begin{abstract}
We evaluated the antibacterial properties of three disinfectants $[2 \%$ chlorhexidine (CHX), $6 \%$ sodium hypochlorite (NaOCl), and 0.01\% urushiol)] against Streptococcus mutans and their effects on bond strength of Scotchbond ${ }^{\mathrm{TM}}$ Universal. The reduction in bacterial growth was evaluated by the colony counting method. Total 105 specimens were assigned to seven groups, according to surface pretreatment: control group (C) without pretreatment; chlorhexidine gluconate with rinse (CR) or without rinse (CD); $\mathrm{NaOCl}$ with rinse (NR) or without rinse (ND); and urushiol with rinse (UR) or without rinse (UD). The shear bond test was performed at a cross-head speed of $0.5 \mathrm{~mm} / \mathrm{min}$. None of the disinfected specimens had viable microbes after a $30 \mathrm{~min}$ incubation. The control group exhibited the strongest bond; however, no significant difference was detected with the disinfectant-treated groups, except weak bonding with ND group. These findings suggest that all disinfectants tested had strong antibacterial capacity and may better be rinsed away.
\end{abstract}

Keywords: Antibacterial capacity, Shear bond strength, Chlorhexidine, Sodium hypochlorite, Urushiol

\section{INTRODUCTION}

Demineralization of hard tooth tissues is caused by bacterial biofilms that produce acid as a result of carbohydrate fermentation ${ }^{1}$. Heterogeneous oral biofilms consist of various types of bacteria embedded in an extracellular matrix. Cariogenic bacteria, such as Streptococcus mutans and Lactobacilli in the biofilm, are major pathogens of caries that metabolize carbohydrates to acids ${ }^{2)}$.

Advanced dental caries that cannot be remineralized should be eradicated by surgical intervention with a bur or other instrument. Under these circumstances, smear layers composed of residual organic and inorganic components are always produced along tooth cavity walls ${ }^{3)}$ and they are usually contaminated with saliva, blood, or microorganisms. Residual bacteria may proliferate in the smear layer beneath a restoration ${ }^{4}$. Therefore, pretreating cavity surfaces with an antibacterial agent is invaluable for eliminating the harmful effects of residual bacteria or their toxins ${ }^{5}$. Branstromm reported that the smear layer should be removed to eliminate microbes ${ }^{6)}$.

Chlorhexidine (CHX) has frequently been applied to tooth cavities ${ }^{7,8}$ prior to placing a restoration because of its broad spectrum antibacterial activity and substantivity $\left(48 \mathrm{~h}^{9)}, 4\right.$ weeks ${ }^{10)}$, and 12 weeks ${ }^{11)}$. CHXpretreated dentin has higher shear bond strength after removing the smear layer and smear plugs ${ }^{12)}$. CHX also minimizes convective and evaporative water fluxes from underlying dentin; thus, enhancing bond strength of self-etch adhesives ${ }^{13)}$. Furthermore, CHX acts as matrix metalloproteinase (MMP) inhibitor; thus, it preserves dentin bond strength.

Sodium hypochlorite $(\mathrm{NaOCl})$ is often used as a chemomechanical agent to remove caries and is used during dentin bonding procedures because of its antibacterial and tissue dissolving properties ${ }^{14)}$. It is presumed that $\mathrm{NaOCl}$ reduces compactness of the smear layer because it eliminates the collagen phase, which increases the bond strength of the self-etching adhesive, as it may enhance diffusivity of the acidic monomers, through water-filled channels between smear layer particles, which increase their size to reach and interact with the underlying dentin surface ${ }^{13)}$. However, there are controversies about the use of these antibacterial agents as cavity disinfectants because of several positive and negative reports about their effects on adhesive bond strength ${ }^{12,15,16)}$.

Urushiol is a cavity disinfectant candidate and a major component of the lacquer tree, which has been used as a folk remedy to relieve abdominal discomfort in the form of boiled chicken soup in Korea. Urushiol has both antibacterial and antioxidative activities ${ }^{17,18}$. Urushiol consists of a catechol substituted with a 15 or 17 carbon alkyl chain (Fig. 1). The antibacterial characteristics of urushiol are thought to be dependent on the degree of unsaturation of the alkyl chain ${ }^{17}$. However, no study has investigated using urushiol as a cavity disinfectant, despite its well-known antibacterial effect.

Therefore, the antibacterial properties of these three agents against $S$. mutans and their effects on selfetching adhesive bond strength to dentin were examined in this study. The null hypotheses tested were (1) no difference in the antibacterial capacity against $S$. mutans among the disinfectants and (2) no reduction in dentin bond strength when the cavity was pretreated with the disinfectants whether they were rinsed off or not. 


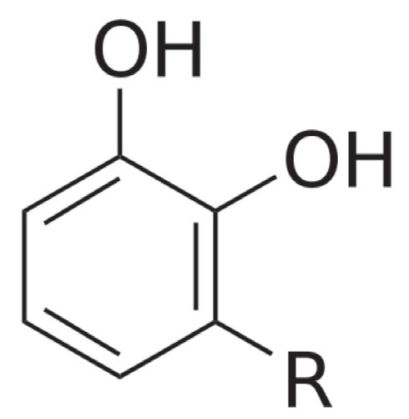

Fig. 1 Structure of typical urushiol.

\section{MATERIALS AND METHODS}

\section{Bacterial strains and culture conditions}

Streptococcus mutans (ATCC 25175) was used to measure the antibacterial activities of $2 \%$ solution of chlorhexidine digluconate (CAVITY CLEANSER ${ }^{\mathrm{TM}}$, Bisco, Schaumburg, IL, USA), $6 \% \mathrm{NaOCl}$ (RC CLEANER, Ilchung Dental, Seoul, South Korea), and 0.01\% urushiol (lacquer tree extract from Japan). The bacterial strain was cultured in brain-heart infusion (BHI) broth alone or in BHI broth containing 1.5\% (w/v) agar at $37^{\circ} \mathrm{C}$.

\section{Antibacterial activity assay}

Streptococcus mutans was grown in BHI broth alone or in $\mathrm{BHI}$ broth containing $2 \% \mathrm{CHX}, 6 \% \mathrm{NaOCl}$, or $0.01 \%$ urushiol at $37^{\circ} \mathrm{C}$. The reduction in bacterial growth was evaluated using the colony counting method. Briefly, a single colony of bacteria was inoculated in $5 \mathrm{~mL}$ BHI medium and incubated for $24 \mathrm{~h}$ at $37^{\circ} \mathrm{C}$ with shaking at $180 \mathrm{rpm}$. The bacterial culture was diluted 1:100 in fresh medium and incubated at $37^{\circ} \mathrm{C}$ until the late-log phase. Approximately $6 \times 10^{7}$ bacterial cells were inoculated into $1 \mathrm{~mL}$ BHI medium containing each of the disinfectants. At $0,30,60$, and $90 \mathrm{~min}$ after inoculating the bacteria, the number of viable bacterial cells in the supernatant was determined by counting colony forming units (CFU) on the BHI agar plates. This analysis was repeated at least three times.

\section{Shear bond strength analysis}

A total of 105 extracted human molars were used in this study. This study was approved by Dankook University, College of Dentistry, South Korea (H-1503/003/006), and all patients provided prior consent. The extracted teeth were stored in thymol solution at $4^{\circ} \mathrm{C}$ and used within 2 weeks. The teeth, including the roots, were embedded in an octagonal pillar-shaped mold filled with self-cure acrylic resin (Ortho-Jet, Lang Dental Mfg, Wheeling, IL, USA) after scaling and cleansing. After the acrylic resin polymerized, the acrylic blocks were removed from the molds, and the occlusal surface was ground perpendicular to the long axis of the teeth with a low-speed diamond disk saw in order to expose a mid-coronal dentin. The dentin surface was polished with \#600-grit silicon carbide paper for 60 s to unify the smear layer.

The specimens were assigned randomly to one of seven main groups $(n=15)$, according to the proposed surface pretreatment: control group without pretreatment (C); $2 \%$ CHX pretreatment without rinse (CD); $6 \% \mathrm{NaOCl}$ pretreatment without rinse (ND); $0.01 \%$ urushiol pretreatment without rinse (UD); $2 \%$ CHX pretreatment with rinse (CR); 6\% $\mathrm{NaOCl}$ pretreatment with rinse (NR); and 0.01\% urushiol pretreatment with rinse (UR).

The disinfectant was applied using a disposable brush tip, and left undisturbed for $20 \mathrm{~s}$. Then, the teeth in the CR, NR, and UR groups were rinsed with water for $10 \mathrm{~s}$, and dried gently with oil-free air for another $10 \mathrm{~s}$. Teeth in the CD, ND, and UD groups were dried without rinse. Scotchbond ${ }^{\mathrm{TM}}$ Universal adhesive (3M ESPE, St. Paul, MN, USA) was applied and brushed on for $20 \mathrm{~s}$ using a fully saturated brush tip and then lightly air-dried for $5 \mathrm{~s}$. The surface was light-cured for $20 \mathrm{~s}$ with a LED curing unit (Elipar Freelight 2, 3M ESPE) with a light output of $750 \mathrm{~mW} / \mathrm{cm}^{2}$.

Composite resin (Filtek Z350 ${ }^{\mathrm{XT}}$, 3M ESPE) was applied carefully to the treated dentin surface by placing the material into a cylindrically shaped split Teflon mold with an internal diameter of $4 \mathrm{~mm}$ and height of $3 \mathrm{~mm}$. The mold was filled incrementally in two $1.5 \mathrm{~mm}$ layers, and each layer was light cured for $20 \mathrm{~s}$ with the same curing unit. The shear test was performed with a compressive load applied at the resin-tooth interface using a mono-beveled chisel-shaped metallic rod at a cross-head speed of $0.5 \mathrm{~mm} / \mathrm{min}$.

Field emission scanning electron microscopic (FE-SEM) analysis

The mid-coronal occlusal dentin of seven molars was used as specimens to examine the effect of the disinfectants on shear bond strength. The dentin surfaces were similarly treated as the shear bond strength specimens. They were mounted on aluminum stubs, sputter-coated with gold/palladium, and examined using a FE-SEM (S-3000H, Hitachi, Tokyo, Japan) operating at $5 \mathrm{kV}$.

\section{Statistical analysis}

Two-way analysis of variance (ANOVA) was used to examine the effects of the disinfectants and their mode of application on dentin bond strength. The independent $t$-test was performed to detect significant differences between subgroups (mode of application; rinsing off or drying only after applying the disinfectants). One-way ANOVA and Tukey's HSD post-hoc tests were used to examine differences in bond strength and antibacterial capacity among the groups. A $p<0.05$ was considered significant. All analyses were carried out with SPSS 19.0 software (SPSS, Chicago, IL, USA).

\section{RESULTS}

No viable microbes were detected after a $30 \mathrm{~min}$ incubation with three of the disinfectants, indicating 
that they had a similar potent antibacterial effect against $S$. mutans when they were used at standard concentrations (2\% $\mathrm{CHX}, 6 \% \mathrm{NaOCl}$, and $0.01 \%$

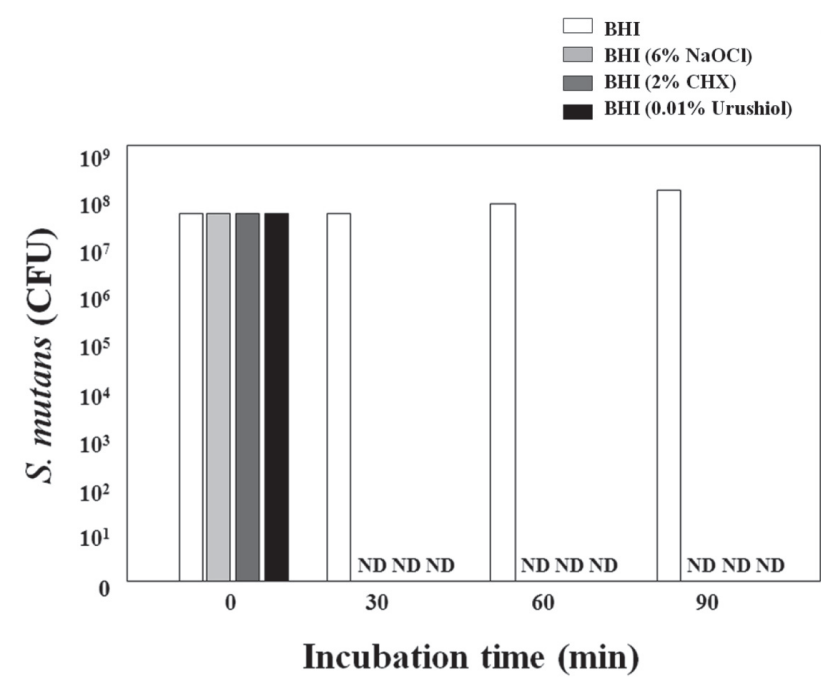

Fig. 2 The numbers of CFUs according to incubation time.

ND: not detected, CFU: colony forming unit urushiol) (Fig. 2).

Mean and standard deviation bond strength values of all groups are shown in Table 1. A two-way ANOVA indicated no differences for the factor "disinfectants" $(p=0.136)$ or for the interaction between factors $(p=0.712)$. However, the factor "mode of application" was significantly different among the groups $(p=0.033)$ (Table 2). The control group exhibited the highest bond strength; however, no significant difference was detected with the disinfectant-treated groups, except the ND group. Among the disinfectant-treated groups, the CR group had the highest bond strength value and the ND group exhibited the lowest value. Groups in which the disinfectants were rinsed off tended to show better shear bond strength than those in which the disinfectants were not rinsed, especially the $\mathrm{NaOCl}$ treatment. The ND group showed significantly lower strength than that of the NR group $(p<0.05)$.

The FE-SEM examination showed that the smear layer and smear plugs covered the dentin surface in the control group (Fig. 3A). However, the three disinfectants removed overlying contaminants at different degrees when they were rinsed off (Figs. 3B-D). On the other hand, some residual contaminants covered the dentin surfaces when the disinfectants remained without rinsing (Figs. 3E-G).

Table 1 Shear bond strength values $(\mathrm{MPa})$

\begin{tabular}{lll}
\hline Group & $n$ & Mean (S. D.) \\
\hline Control & 15 & $16.74(5.14)^{\mathrm{a}}$ \\
CR & 15 & $15.07(4.86)^{\mathrm{a}, \mathrm{b}}$ \\
NR & 15 & $13.45(3.50)^{\mathrm{a}, \mathrm{b}}$ \\
UR & 15 & $14.84(4.12)^{\mathrm{a}, \mathrm{b}}$ \\
CD & 15 & $14.10(5.56)^{\mathrm{a}, \mathrm{b}}$ \\
ND & 15 & $10.96(4.57)^{\mathrm{b}}$ \\
UD & 15 & $12.06(4.47)^{\mathrm{a}, \mathrm{b}}$ \\
\hline
\end{tabular}

Same superscripts indicate mean values with no statistically significant difference $(p>0.05)$.

Table 2 Two-way analysis of variance of shear bond strength

\begin{tabular}{lcccrr}
\hline \multicolumn{1}{c}{ Source } & Type III Sum of Squares & df & Mean Square & $F$ & Sig. \\
\hline Corrected model & $196.38^{\mathrm{a}}$ & 5 & 39.28 & 1.89 & 0.104 \\
Intercept & $16,192.51$ & 1 & $16,192.51$ & 779.80 & 0.000 \\
Disinfectants (A) & 84.85 & 2 & 42.42 & 2.04 & 0.136 \\
Mode of application (B) & 97.37 & 1 & 97.37 & 0.69 \\
A B & 14.16 & 2 & 20.77 & - & -0.34 \\
Error & $1,744.25$ & 84 & - & - \\
Total & $18,133.14$ & 90 & - & - \\
Corrected Total & $1,940.63$ & 89 & - & - \\
\hline
\end{tabular}

a. $R$ Squared=0.101 (Adjusted R Squared=0.048) 

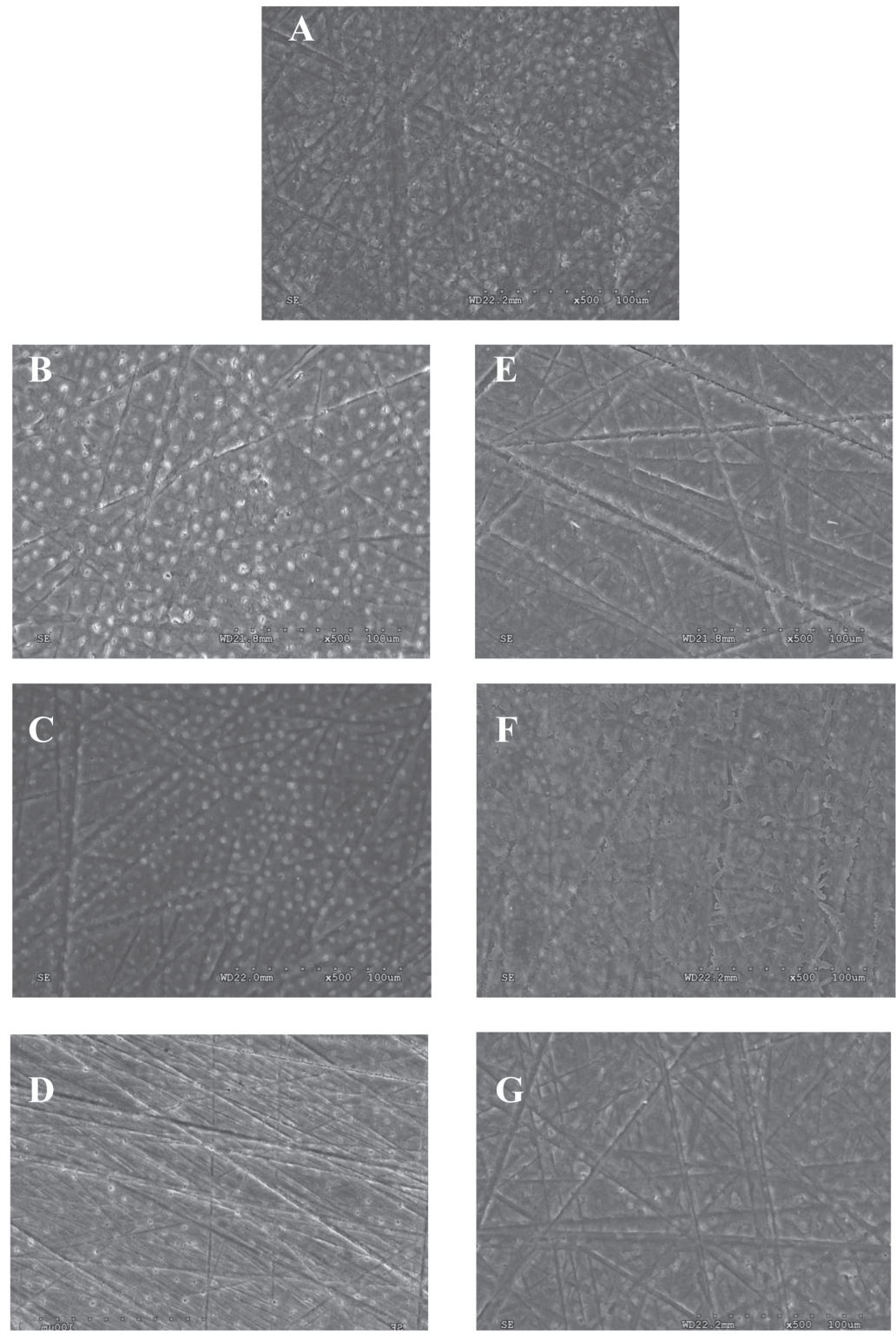

Fig. 3 FE-SEM images $(\times 500)$ : (A) Control group, (B) CR group, (C) NR group, (D) UR group, (E) CD group, (F) ND group, (G) UD group.

\section{DISCUSSION}

Pulp damage after restoration is thought to be caused by bacteria passing between the cavity walls and the filling material or through microleakage ${ }^{19)}$. A dentin adhesive with long-lasting antibacterial activity against diverse microbes should prevent bacteria from passing toward the pulp. Moreover, if the microbes remaining after preparing the tooth could be removed by disinfecting the cavity before restoration, it would help reduce damage by obtaining relatively clean cavity walls.

Streptococcus mutans was chosen as the target microorganism because it is a well known major pathogen of caries ${ }^{20)}$. These bacteria are small enough to move rapidly and penetrate easily into the dentinal tubules ${ }^{21)}$, which may lead to pulp damage. The antibacterial capacity of three disinfectants against $S$. mutans was examined in this study by counting colony forming units. No S. mutans was detected after the 30 min incubation with the three disinfectants $(2 \% \mathrm{CHX}$, $6 \% \mathrm{NaOCl}$, and $0.01 \%$ urushiol). Therefore, they all seemed to have very potent antibacterial characteristics. Based on the result that urushiol was bactericidal at a very low concentration (0.01 wt\%), it may be useful to apply this solution to the cavity walls as a cavity 
disinfectant. Thus, our first hypothesis was accepted.

Each disinfectant has its own antibacterial mechanism. CHX is a positively charged hydrophobic and lipophilic molecule that interacts with phospholipids and lipopolysaccharides in the bacterial cell membrane and enters the cell ${ }^{22)}$. CHX gluconate is a stable watersoluble salt that readily dissociates and releases a positively charged CHX component ${ }^{23)}$. CHX (2\%) is bactericidal by precipitating cytoplasmic contents, leading to cell death ${ }^{24)}$. $\mathrm{NaOCl}$ alters cellular metabolism and destroys phospholipids. It also promotes formation of chloramines, which have an oxidative action that irreversibly inactivates bacterial enzymes ${ }^{25}$. Urushiol disrupts the bacterial cell membrane ${ }^{26}$. It promotes bleb formation and lysis of Helicobacter pylori. This action is so quick that most $H$. pylori lysis occurs within $10 \mathrm{~min}$. One study reported that urushiol can be used safely as an antimicrobial agent without systemic complications ${ }^{27}$.

Although these disinfectants have potent antibacterial capacity, it is useless if they negatively impact the bond strength of a restoration. The mode of applying the disinfectant to the cavity may also affect bond strength, such as rinsing off or drying only without rinsing. The influence of these two factors on shear bond strength of a self-etching adhesive was examined in this study.

The control group exhibited the strongest bond strength, and the groups pretreated with a disinfectant were not different, except weak bonding with ND group. No significant differences in bond strength were detected among the groups treated with the three disinfectants.

Our CHX results were in agreement with those of other studies, reporting that CHX does not affect shear bond strength to dentin ${ }^{28,299}$. However, one study showed that varied concentrations of chlorine ions and crystal-shaped precipitates were formed on the CHX treated dentin surface, this resulted in significantly lower bond strength ${ }^{15}$. It has also been reported that CHX reduces bond strength due to its binding to loose apatite remnants within the smear layer, resulting in more pronounced nanoleakage of a self-etching adhesive to dentin ${ }^{30}$. On the other hand, other studies have reported that CHX-treated dentin results in higher shear bond strength than that of an untreated control group. The authors attributed the improved bond strength to removal of the smear layer and smear plugs, which prevented direct contact of the self-etching adhesive with dentin; consequently, removing the smear layer facilitates formation of a stronger and more homogeneous hybrid layer ${ }^{31,32}$.

Applying $\mathrm{NaOCl}$ in this study also resulted in no difference in bond strength with the control group after it was rinsed off, which agrees with a previous study reporting that $\mathrm{NaOCl}$ does not influence bond strength to dentin ${ }^{33)}$. However, we observed significantly lower shear bond strength when $\mathrm{NaOCl}$ remained without rinsing. Previous studies have reported the same results like this study, that is, better or worse bond strength using $\mathrm{NaOCl}$. Significantly increased bond strength was observed and was attributed to eliminating the collagen layer, leading to better penetration of the adhesive into intertubular dentin and possible removal of the smear layer ${ }^{34,35)}$. On the other hand, significantly decreased dentin bond strength was reported and was attributed to organic monomers in the adhesive system that could not sufficiently penetrate into the demineralized dentin because of damage to the organic component of $\operatorname{dentin}^{36)}$.

Urushiol, like CHX, recorded similar shear bond strength to that of the control group regardless of rinsing. Urushiol is a very good candidate cavity cleanser because of its excellent antibacterial capacity and little change in dentin bond strength at a very low concentration.

A two-way ANOVA revealed that the factor "mode of application" resulted in a significant difference in shear bond strength. Although application mode did not influence bond strength when CHX and urushiol were tested, significantly lower bond strength was detected in the ND group compared to that in the NR group. Therefore, the second hypothesis was partly rejected. We conclude that rinsing the disinfectant away is the best method to clean the cavity.

The FE-SEM examination of the dentin surfaces revealed that the smear layer and smear plugs remained in the control group (Fig. 3A). Smear layers were removed at different degrees in the groups treated with the disinfectants when they were rinsed off (Figs. 3B-D). However, some residual contaminants covered the dentin surfaces when the disinfectants remained without rinsing (Figs. 3E-G). These residual contaminants may hinder direct contact with resin components and tooth substances. These kinds of dentin surface changes have been reported previously ${ }^{37}$. Although we have provided clear evidence that the dentin surfaces were altered similarly with those of previous studies, the bond strength results varied. These bond strength discrepancies among studies may be attributed to differences in sample preparation, application mode, or time. Thus, the results of these studies should be analyzed with caution.

One possible shortcoming of the study is that Streptococcus mutans was sole target microorganism used in this study because of its well-known pathogenicity in dental caries. However, dental plaque is a complicated ecosystem of approximately 1,000 bacterial species ${ }^{38}$. Therefore, use of a microcosm model in future studies would be preferable ${ }^{39}$. There are many factors affecting dentin bond strength. Therefore, further studies must consider these factors.

\section{CONCLUSION}

Under the limitations of this study, we conclude that $0.01 \%$ urushiol had strong antibacterial capacity against S. mutans as well-known cavity disinfectants tested ( $2 \%$ $\mathrm{CHX}$ and $6 \% \mathrm{NaOCl}$ ) and that the disinfectants may better be rinsed away when they are used to clean the cavity walls to achieve optimum bonding performance. 


\section{ACKNOWLEDGMENTS}

The present research was conducted by the research fund of Dankook university in 2013.

\section{REFERENCES}

1) Opdam NJ, Bronkhorst EM, Roeters JM, Loomans BA. A retrospective clinical study on longevity of posterior composite and amalgam restorations. Dent Mater 2007; 23: 2-8.

2) Takahashi N, Nyvad B. Caries ecology revisited: microbial dynamics and the caries process. Caries Res 2008; 42: 409418.

3) Pashley DH. Smear layer: physiological considerations. Oper Dent 1984; (Suppl. 3): 13-29.

4) Meiers JC, Shook LW. Effect of disinfectants on the bond strength of composite to dentin. Am J Dent 1996; 9: 11-14.

5) Ersin NK, Uzel A, Aykut A, Candan U, Eronat C. Inhibition of cultivable bacteria by chlorhexidine treatment of dentin lesions treated with the ART technique. Caries Res 2006; 40: 172-177.

6) Brannstromm M. The cause of postrestorative sensitivity and its prevention. J Endod 1986; 12: 475-481.

7) Leonardo MR, Tanomaru-Filho M, Silva LAB, Nelson-Filho $\mathrm{P}$, Bonifacio KC, Ito IY. In vivo antimicrobial activity of $2 \%$ chlorhexidine used as a root canal irrigation solution. J Endod 1999; 25: 167-171.

8) Khademi AA, Mohammadi Z, Havaee A. Evaluation of the antibacterial substantivity of several intra-canal agents. Aust Endod J 2006; 32: 112-115.

9) Rosenthal S, Spangberg L, Safavi KE. Chlorhexidine substantivity in root canal dentine. Oral Surg Oral Med Oral Pathol Oral Radiol Endod 2004; 98: 488-492.

10) Fardal O, Turnbull RS. A review of the literature on use of chlorhexidine in dentistry. J Am Dent Assoc 1986; 112: 863869.

11) Glermo P. Chlorhexidine and related compounds. J Dent Res 1989; 68: 1602-1608.

12) Mohammed Hassan A, Ali Goda A, Baroudi K. The effect of different disinfecting agents on bond strength of resin composites. Int J Dent 2014:231235. doi: 10.1155/2014/231235. Epub 2014 Nov 13.

13) Carrilho MR, Carvalho RM, de Goes MF, di Hipolito V, Geraldeli S, Tay FR, Pashley DH, Tjaderhane L. Chlorhexidine preserves dentin bond in vitro. J Dent Res 2007; 86: 90-94.

14) Correr GM, Alonso RCB, Grando MF, Borges AFS, PuppinRontani RM. Effect of sodium hypochlorite on primary dentin -a scanning electron microscopy (SEM) Evaluation. J Dent 2006; 34: 454-459.

15) Di Hipólito V, Rodrigues FP, Piveta FB, Azevedo Lda C, Bruschi Alonso RC, Silikas N, Carvalho RM, De Goes MF, Perlatti D'Alpino PH. Effectiveness of self-adhesive luting cements in bonding to chlorhexidine treated dentin. Dent Mater 2012; 28: 495-501.

16) Gwinnett AJ. Effect of cavity disinfection on bond strength to dentin. J Esthet Dent 1992; 4: 11-13.

17) Kim MJ, Choi YH, Kim WG, Kwak SS. Antioxidative activity of urushiol derivatives from the sap of lacquer tree. Korean J Plant Resour 1997; 10: 227-230.

18) Kim MJ, Kim CJ, Kwak SS. Antifungal activity of urushiol component in the sap of Korean lacquer tree (Rhus vernicifera Stokes). Korean J Plant Resour 1997; 10: 231-234.

19) Camps J, Dejou J, Remusat M, About I. Factors influencing pulpal response to cavity restorations. Dent Mater 2000; 16: 432-440.

20) Kim JS, Shin DH. Inhibitory effect on Streptococcus mutans and mechanical properties of the chitosan containing composite resin. Restor Dent Endod 2013; 38: 36-42.

21) Zivković S, Bojović S, Palvica D. Bacterial penetration of restored cavities. Oral Surg Oral Med Oral Pathol Oral Radiol Endod 2001; 91: 353-358.

22) Athanassiadis B, Abbott PV, Walsh LJ. The use of calcium hydroxide, antibiotics and biocides as antimicrobial medicaments in endodontics. Aust Dent J 2007; 52(Suppl): S64-82.

23) Greenstein G, Berman C, Jaffin R. Chlorhexidine: an adjunct to periodontal therapy. J Periodontol 1986; 57: 370-376.

24) Gomes BP, Souza SF, Ferraz CC, Teixeira FB, Zaia AA, Valdrighi L, Souza-Filho FJ. Effectiveness of $2 \%$ chlorhexidine gel and calcium hydroxide against Enterococcus faecalis in bovine root dentine in vitro. Int Endod J 2003; 36: 267-275.

25) Guida A. Mechanism of action of sodium hypochlorite and its effects on dentin. Minerva Stomatol 2006; 55: 471-482.

26) Suk KT, Kim HS, Kim MY, Kim JW, Uh Y, Jang IH, Kim SK, Choi EH, Kim MJ, Joo JS, Baik SK. In vitro antibacterial and morphological effects of the urushiol component of the sap of the Korean lacquer tree (Rhus vernicifera Stokes) on Helicobacter pylori. J Korean Med Sci 2010; 25: 399-404.

27) Suk KT, Baik SK, Kim HS, Park SM, Paeng KJ, Uh Y, Jang IH, Cho MY, Choi EH, Kim MJ, Ham YL. Antibacterial effects of the urushiol component in the sap of the lacquer tree (Rhus verniciflua Stokes) on Helicobacter pylori. Helicobacter 2011; 16: $434-443$

28) de Castro FL, de Andrade MF, Duarte Júnior SL, Vaz LG, Ahid FJ. Effect of $2 \%$ chlorhexidine on microtensile bond strength of composite to dentin. J Adhes Dent 2003; 5: 129138.

29) Mobarak EH, El-Korashy DI, Pashley DH. Effect of chlorhexidine concentrations on micro-shear bond strength of self-etch adhesive to normal and caries-affected dentin. Am J Dent 2010; 23: 217-222.

30) Hiraishi N, Yiu CK, King NM, Tay FR. Effect of $2 \%$ chlorhexidine on dentin microtensile bond strengths and nanoleakage of luting cements. J Dent 2009; 37: 440-448.

31) Soares CJ, Castro CG, Santos Filho PC, da Mota AS. Effect of previous treatments on bond strength of two self-etching adhesive systems to dental substrate. J Adhes Dent 2007; 9: 291-296.

32) Jacques P, Hebling J. Effect of dentin conditioners on the microtensile bond strength of a conventional and a selfetching primer adhesive system. Dent Mater 2005; 21: 103109.

33) Correr GM, Puppin-Rontani RM, Correr-Sobrinho L, Sinhoret MA, Consani S. Effect of sodium hypochlorite on dentin bonding in primary teeth. J Adhes Dent 2004; 6: 307-312.

34) Fawzy AS, Amer MA, El-Askary FS. Sodium hypochlorite as dentin pretreatment for etch-and-rinse single bottle and two-step self-etching adhesives: atomic force microscope and tensile bond strength evaluation. J Adhes Dent 2008; 10: 135144.

35) Prati C, Chersoni S, Pashley DH. Effect of removal of surface collagen fibrils on resin-dentin bonding. Dent Mater 1999; 15: 323-331.

36) Ozturk B, Ozer F. Effect of $\mathrm{NaOCl}$ on bond strengths of bonding agents to pulp chamber lateral walls. J Endod 2004; 30: 362-365.

37) Hiraishi N, Yiu CK, King NM, Tay FR. Effect of chlorhexidine incorporation into a self-etching primer on dentine bond strength of a luting cement. J Dent 2010; 38: 496-502.

38) ten Cate JM. Biofilms, a new approach to the microbiology of dental plaque. Odontology 2006; 94: 1-9.

39) McBain AJ. In vitro biofilm models: an overview. Adv Appl Microbiol 2009; 69: 99-132. 